\title{
Epidemiology and hypothetical transmission cycles of Trichinella infections in the Greater Kruger National Park of South Africa: an example of host-parasite interactions in an environment with minimal human interactions
}

Louis J. La Grange ${ }^{1,2, a}$, and Samson Mukaratirwa $a^{2,3, a}$

${ }^{1}$ Department of Agriculture, Rural Development, Land and Environmental Affairs, Chief Directorate Veterinary Services, Veterinary Public Health, Private Bag X11309, Mbombela 1200, South Africa

${ }^{2}$ University of KwaZulu-Natal, School of Life Sciences, Westville Campus, Durban 4000, South Africa

${ }^{3}$ One Health Center for Zoonoses and Tropical Veterinary Medicine, Ross University School of Veterinary Medicine, P.O. Box 334, St Kitts, Basseterre, West Indies

Received 13 January 2020, Accepted 24 February 2020, Published online 12 March 2020

\begin{abstract}
Knowledge on the epidemiology, host range and transmission of Trichinella spp. infections in different ecological zones in southern Africa including areas of wildlife-human interface is limited. The majority of reports on Trichinella infections in sub-Saharan Africa were from wildlife resident in protected areas. Elucidation of the epidemiology of the infections and the prediction of hosts involved in the sylvatic cycles within specific ecological niches is critical. Of recent, there have been reports of Trichinella infections in several wildlife species within the Greater Kruger National Park (GKNP) of South Africa, which has prompted the revision and update of published hypothetical transmission cycles including the hypothetical options based previously on the biology and feeding behaviour of wildlife hosts confined to the GKNP. Using data gathered from surveillance studies and reports spanning the period 1964-2019, confirmed transmission cycles and revised hypothesized transmission cycles of three known Trichinella species (T. zimbabwensis, Trichinella T8 and T. nelsoni) are presented. These were formulated based on the epidemiological factors, feeding habits of hosts and prevalence data gathered from the GKNP. We presume that the formulated sylvatic cycles may be extrapolated to similar national parks and wildlife protected areas in sub-Saharan Africa where the same host and parasite species are known to occur. The anecdotal nature of some of the presented data confirms the need for more intense epidemiological surveillance in national parks and wildlife protected areas in the rest of sub-Saharan Africa to unravel the epidemiology of Trichinella infections in these unique and diverse protected landscapes.
\end{abstract}

Key words: Trichinella, Kruger National Park, South Africa.

Résumé - Épidémiologie et cycles de transmission hypothétiques des infections à Trichinella dans le Grand Parc National Kruger en Afrique du Sud : un exemple d'interactions hôtes-parasites dans un environnement où les interactions humaines sont minimales. Les connaissances sur l'épidémiologie, la gamme d'hôtes et la transmission des infections à Trichinella spp. dans différentes zones écologiques d'Afrique australe, y compris les zones d'interface faune-homme, sont limitées. La majorité des signalements d'infections à Trichinella en Afrique subsaharienne proviennent animaux sauvages résidant dans des zones protégées. L'élucidation de l'épidémiologie des infections et la prévision des hôtes impliqués dans les cycles sylvatiques au sein de niches écologiques spécifiques sont essentielles. Récemment, des infections à Trichinella ont été signalées chez plusieurs espèces sauvages dans le Grand Parc National Kruger (GPNK) en Afrique du Sud, ce qui a incité à la révision et à la mise à jour des cycles de transmission hypothétiques publiés, y compris les options hypothétiques basées précédemment sur la biologie et le comportement alimentaire des hôtes de la faune sauvage confinés au GPNK. À partir des données des études de surveillance et de rapports couvrant la période 1964-2019, les cycles de transmission confirmés et les cycles de transmission hypothétiques révisés de trois espèces connues de Trichinella (T. zimbabwensis, Trichinella T8 et T. nelsoni) sont présentés. Ceux-ci ont été formulés sur la base des facteurs épidémiologiques, des habitudes alimentaires des hôtes et des données de prévalence recueillies au GPNK. Nous supposons que les cycles sylvatiques formulés peuvent être extrapolés aux parcs nationaux et zones protégées

*Corresponding author: mukaratirwa@ukzn. ac.za

${ }^{a}$ Both authors contributed equally to the manuscript.

This is an Open Access article distributed under the terms of the Creative Commons Attribution License (https://creativecommons.org/licenses/by/4.0), which permits unrestricted use, distribution, and reproduction in any medium, provided the original work is properly cited. 
similaires en Afrique subsaharienne, où les mêmes hôtes et espèces de parasites sont connues. La nature anecdotique de certaines des données présentées confirme la nécessité d'une surveillance épidémiologique plus intense dans les parcs nationaux et zones protégées du reste de l'Afrique subsaharienne pour démêler l'épidémiologie des infections à Trichinella dans ces paysages protégés uniques et diversifiés.

\section{Introduction}

Nematodes of the genus Trichinella are zoonotic and have a cosmopolitan distribution and infect an array of hosts ranging from cold-blooded reptiles to birds and mammals [53, 65, 70, 81]. Ten species are known to exist within the genus; Trichinella murrelli Pozio \& La Rosa, 2000 [71], T. papuae Pozio et al., 1999 [77], T. nativa Britov \& Boev, 1972 [6], T. britovi Pozio et al., 1992 [73], T. spiralis Owen, 1835 [59], T. pseudospiralis Garkavi, 1972 [17], T. nelsoni Britov \& Boev, 1972 [6], T. patagoniensis Krivokapich et al., 2012 [34], T. zimbabwensis Pozio et al., 2002 [69] and Trichinella T13, Sharma, 2019; Sharma et al., 2019 [89, 90], as well as three additional genotypes, Trichinella T6 Pozio et al., 1992 [73], Trichinella T8 Pozio et al., 1992 [73] and Trichinella T9 Nagano et al., 1999 [55]. At least four species of Trichinella are known to circulate in sub-Saharan Africa, including T. nelsoni, Trichinella T8, T. britovi and T. zimbabwensis [53]. Of the four Trichinella species known to circulate in this region, all except $T$. britovi, have been reported in the GKNP $[53,54]$. Mukaratirwa et al. [53, 54] confirmed lions (Panthera leo) and hyaenas (Crocuta crocuta) to be the major reservoirs for Trichinella infections in the Greater Kruger National Park (GKNP), based on reported prevalence data. However, of late, Trichinella spp. infections have been confirmed in at least six mammalian and two reptile species from the GKNP [38, 40, 43, 54, 79] as well as Trichinella-like infections in at least six additional mammalian hosts [43, 54, 100, 101]. Despite the diverse host range and the fact that South Africa has the highest reported prevalence of Trichinella in sub-Saharan Africa [54], no human cases have been reported from South Africa to date.

Trichinella spp. infection is notifiable and listed in the Terrestrial Animal Health Code of the World Organization for Animal Health [58]. Owing not only to its potential economic and public health impact as a food-borne parasitic zoonosis, the diverse nature of the genus and subsequently diverse host range has led to a myriad of investigations aimed at elucidating not only its evolutionary expansion [80] but also the host-parasite relationships that exist within different ecological niches [64, 66, 70, 75, 78]. Factors influencing these relationships, however, are equally diverse and preclude any definitive report on the epidemiology of any one Trichinella species, especially where the natural sylvatic cycles are concerned.

The GKNP of South Africa represents a protected area where the abundance of sylvatic host species ensures both Trichinella spp. survival and transmission [43]. Scholtz et al. [88] reported that 1982 plant, 517 bird, 147 mammal and 21 reptile species exist in the approximate $20,000 \mathrm{~km}^{2}$ of the Kruger National Park (KNP) of South Africa. Several pieces of private land are additionally included by proclamation as part of the protected area, adding approximately another 37,430 ha which, collectively is known as the GKNP [88]. This speciesrich and diverse habitat is maintained by intricate preypredator-scavenger interactions, all of which are well protected within its borders. This creates an optimal system for species of the genus Trichinella to thrive.

However, the situation in the KNP is not unique and similarly optimal conditions may be expected in other national protected areas in sub-Saharan Africa such as the Serengeti (Tanzania), Kafue (Zambia), Hwange (Zimbabwe) and Gorongosa (Mozambique).

In this study, we reviewed published information on Trichinella infection in wildlife in the GKNP of South Africa from 1964 to 2019 and based on the results, the authors constructed complete hypothetical transmission cycles for the three taxa known to circulate in the GKNP. In justifying the hypotheses, the factors which may be influencing the establishment of these cycles are discussed, together with the potential of spillage into domestic environments and risk for human infections.

Pozio [65] noted differences in infection between host species as a result of unique host characteristics including diet, life span, distribution, behaviour and human interaction. Gottstein et al. [19] additionally noted that the survival of encysted larvae in host musculature is also influenced by host immunity, ultimately influencing the overall epidemiology of infection. Similarly, specific evolutionary adaptations among individual species of the genus affect their infectivity to specific hosts as well as epidemiology and survival in specific environments $[64,80]$. These factors cannot be considered as constant either and are continually changing; most notably as a result of human activity and interaction, which influences environments, host species and parasites alike [12, 85]. However, these changes are, for the most part, slow in development, allowing at least some consistency as far as parasite transmission cycles are concerned. This allows for the elucidation of current epidemiology of Trichinella infections and more importantly, the prediction of probable host-parasite cycles within a set ecological niche.

These host-parasite interactions are likely to be more constant in environments such as national parks and wildlife protected areas where established relationships remain relatively unchanged through minimal human interference. This is especially true for Trichinella infections that evidently have a larger biomass in sylvatic animals compared to domestic animals [75].

\section{Materials and methods Study area}

The KNP (Fig. 1) is situated in the North-Eastern corner of South Africa and is bordered by Zimbabwe to the north and 


\section{Greater Kruger National Park (GKNP) Complex}

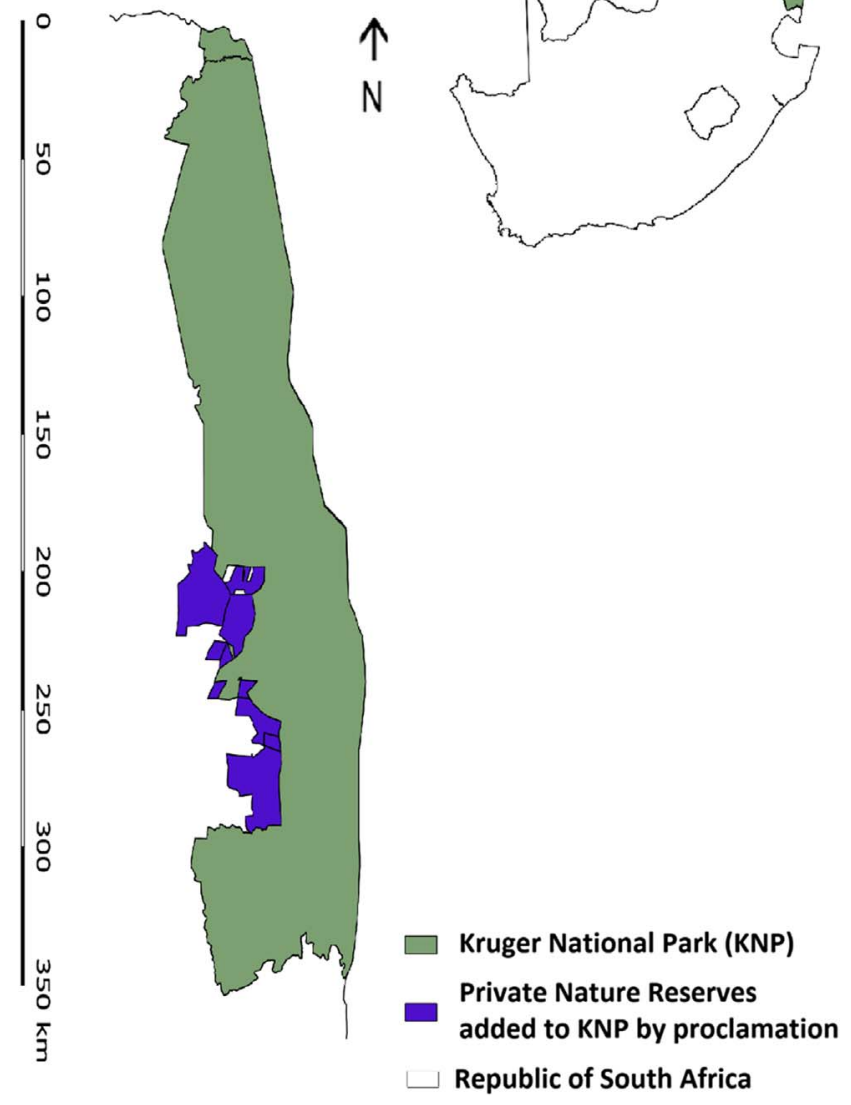

Figure 1. Map showing the Greater Kruger National Park of South Africa.

Mozambique to the east [87]. This protected area covers almost 2 million hectares and boasts a diverse fauna comprising among others more than 150 mammal, 500 bird and 116 reptile species inhabiting its diverse tropical to sub-tropical "Biological Environment" [87]. The western- and south-western borders of the park are flanked by large communal areas and several private nature reserves while the southern border is mainly flanked by private agricultural and game farms. The impressive size of the GKNP allows for interactions between large predator and prey species which can be considered "near-natural" [87]. These conditions have undoubtedly favoured, specifically in respect of Trichinella spp. infections, the establishment and maintenance of unique parasite-host relationships.

\section{Search strategy}

A search in Google Scholar, PubMed, AJOL and EBSCO Host database was conducted using the following terms and Boolean operators (AND, OR): Trichinella AND Wildlife; Trichinella infections in wildlife AND Kruger National Park; Trichinella spp, Trichinella zimbabwensis, Trichinella T8, Trichinella nelsoni AND Kruger National Park. Search results were carefully scrutinized and the relevant articles were selected for inclusion in the study. Some of the references of identified articles were additionally used to check for other relevant articles. The inclusion criteria included "all published peerreviewed articles reporting on Trichinella infection in wildlife/livestock/humans in the GKNP from 1964 to 2019”.

\section{Construction of hypothetical transmission cycles}

The probability of $T$. nelsoni, Trichinella $\mathrm{T} 8$ and T. zimbabwensis parasites being transmitted among different wildlife hosts present in the GKNP was inferred from published literature on dietary habits of specific host species (Tables 1 and 2). No absolute or quantitative values could be attributed to these probabilities by any statistical means. The multifactorial and constantly changing nature of the multitude of ecological factors that may influence host interactions and subsequent parasite epidemiology precludes such an analysis. Furthermore, reports and publications from other sub-Saharan countries involving similar host species were also reviewed to provide supplementary data for the information portrayed in the hypothetical transmission cycles (Table 3).

Based on the available prevalence data, lions are proposed to be the main reservoirs for both T. nelsoni and Trichinella T8, while crocodiles are considered to be main reservoirs for T. zimbabwensis. However, there is limited information on additional and other potential reservoirs, and in most cases the numbers of animals screened for Trichinella spp. infection are very low. It is also important to consider the overall biomass of each potential host species within the ecological framework being assessed. Species representing a larger biomass will require a higher number of individuals to be tested compared to species with a smaller biomass in order to reach conclusive evidence in respect of identifying main reservoirs. In the case of rodents, this problem is further compounded by the fact that vertical parasite transmission is possible via both the transmammary and transplacental routes [45].

\section{Results}

\section{Trichinella species reported in the GKNP}

From the beginning of Trichinella surveillance studies in South Africa in 1964 to the end of 2016, at least two species and one genotype have been confirmed across six mammalian and two reptilian hosts from the GKNP [38, 40, 43, 54, 79]. Trichinella-like infections have additionally been reported in six other mammalian hosts, but species confirmation of the parasite was not possible $[43,54,100,101]$. The unidentified isolates, for the most part, were generally believed to be one or more of the parasite species known to circulate in the area. A Trichinella-like infection has also been reported in a Marsh owl (Asio capensis), possibly suggesting the existence of an additional Trichinella specie not known to occur on the African continent or a different tissue-dwelling nematode/larva not related to Trichinella [54] (Table 2).

In the GKNP, the prevalence of T. nelsoni in lions and hyaenas was reported to be $3 / 98(3.06 \%)$ and $0 / 26(0 \%)$, respectively [54]. It is important to note that the majority of these isolates (11/21) and (14/17) found in lions and hyaenas 
Table 1. Predation/scavenging habits of wildlife species reported to harbour Trichinella spp. in sub-Saharan Africa (Events of predation/ scavenging among species depicted below are not indicative of any degree of probability but merely suggest a possibility of such events occurring based on the literature cited).

\begin{tabular}{|c|c|c|c|}
\hline Animal species & Common Name & Species predated/scavenged & References \\
\hline \multirow{7}{*}{ Panthera leo } & Lion & Warthog & {$[10,21,61]$} \\
\hline & & Rodents & [10] \\
\hline & & Baboon & {$[7,21]$} \\
\hline & & Hyaena & {$[63,84]$} \\
\hline & & Leopard, wild dog, cheetah & [63] \\
\hline & & Crocodile & [92] \\
\hline & & Lion & [57] \\
\hline \multirow[t]{4}{*}{ Panthera pardus } & Leopard & Hyaena, lion, wild dog, cheetah & {$[63]$} \\
\hline & & Crocodiles & {$[63,92]$} \\
\hline & & Baboon & {$[7,27]$} \\
\hline & & Rodents & {$[26]$} \\
\hline Varanus niloticus & Nile monitor & Rodents, juvenile crocodiles & [95] \\
\hline \multirow[t]{3}{*}{ Crocuta crocuta } & Spotted hyaena & Warthog, baboon & {$[20]$} \\
\hline & & Lion & {$[63,84]$} \\
\hline & & Leopard, cheetah & [63] \\
\hline Felis silvestris lybica & African Wildcat & Rodents, carrion (unspecified) & [24] \\
\hline \multirow[t]{2}{*}{ Canis mesomelas } & Black-backed jackal & Cheetah & [63] \\
\hline & & Rodents, carrion (unspecified) & {$[3,5,23]$} \\
\hline Civettictis civetta & African civet & Rodents, carrion (unspecified) & [5] \\
\hline Genetta genetta & Small spotted genet & Rodents & [39] \\
\hline \multirow[t]{2}{*}{ Papio ursinus } & Chacma baboon & Baboon & {$[62]$} \\
\hline & & Rodents & {$[1]$} \\
\hline Praomys natalensis & Multimammate mouse & Multimammate mouse & [26] \\
\hline \multirow{4}{*}{ Crocodylus niloticus } & Nile crocodile & Leopard & [63] \\
\hline & & Crocodile & [92] \\
\hline & & Nile monitor & [95] \\
\hline & & Lion, hyaena, warthog, baboon & [16] \\
\hline Potamochoerus larvatus ${ }^{\mathrm{a}}$ & Bushpig & Carrion (unspecified) & [91] \\
\hline \multirow[t]{2}{*}{ Phacochoerus africanus ${ }^{\mathrm{a}}$} & Warthog & Hyaena & [84] \\
\hline & & Civet, carrion (unspecified) & [9] \\
\hline Canis adustis ${ }^{\mathrm{a}}$ & Side-striped jackal & Rodents & {$[3,5]$} \\
\hline Acinonyx jubatus ${ }^{\mathrm{a}}$ & Cheetah & Rodents, carrion (unspecified) & [47] \\
\hline \multirow{2}{*}{ Leptailurus serval $^{\mathrm{a}}$} & Serval & Warthog & [82] \\
\hline & & Rodents, small spotted genet & \\
\hline Otocyon megalotis ${ }^{\mathrm{a}}$ & Bat-eared fox & Rodents & [96] \\
\hline Ichneumia albicauda ${ }^{\mathrm{a}}$ & White-tailed mongoose & Rodents & [11] \\
\hline Hyaena hyaena ${ }^{\mathrm{a}}$ & Striped hyaena & Rodents, carrion (unspecified) & [98] \\
\hline
\end{tabular}

${ }^{\text {a }}$ Species native to GKNP and known host of Trichinella spp. elsewhere.

respectively, were not identified to species level [54] and thus the actual prevalence in GKNP could be higher than reported. Based on the overall prevalence of T. nelsoni in sub-Saharan Africa (Table 3) and the GKNP (Table 2), hyaenas and lions are considered to be the main reservoirs for this parasite species in the GKNP, as may be the general case with similar habitats in other African countries [43, 53].

In the GKNP, only a single leopard $(1 / 7,14 \%)$ tested positive for T. nelsoni [54] and the same species has previously been isolated from leopards in Kenya [66] and Tanzania [67]. La Grange et al. [38] described a mixed infection of T. nelsoni and Trichinella T8 in a leopard from the GKNP and based on the dietary habits of the species [4, 20, 42, 94], we hypothesise that other small mammalian carnivores may serve as an important source of infection to these animals in the GKNP.

Similar to $T$. nelsoni, genotype Trichinella $\mathrm{T} 8$ has been found in low prevalence in lions $(4 / 98,4 \%)$, hyaenas
$(1 / 26,3.8 \%)[43,54,76]$ and leopards $(1 / 7,14 \%)$ from the GKNP [38, 54]. Again, as in the case of T. nelsoni, many Trichinella spp. isolates found were reported prior to the advent of molecular characterisation techniques, and thus the parasite species involved remain unknown. Data on the actual distribution and prevalence of Trichinella T8 are still fragmented. Although closely related to Trichinella T8, Trichinella britovi has never been isolated from South African wildlife. Pozio and Murrell [75] confirmed the geographical distribution of T. britovi to include amongst others Northern and Western Africa, whereas Trichinella T8 is confined to the South Western and South Eastern parts of Africa. Pozio et al. [78] hypothesized that large natural barriers such as the Zaire lake basin and river Cross of Nigeria, together with environmental changes, may have contributed to the evolution of these two unique taxa.

Trichinella zimbabwensis was previously isolated from wild Nile crocodiles (Crocodylus niloticus) in the KNP and just 
Table 2. Occurrence of Trichinella spp. in wildlife species from the Greater Kruger National Park, South Africa, from 1964 to 2019.

\begin{tabular}{llccccccc}
\hline Animal species & \multicolumn{1}{c}{ Common name } & No positive/tested & $\begin{array}{c}\text { Total prevalence } \\
(\%)\end{array}$ & Tz & Tn & T8 & NID & References \\
\hline Panthera leo & Lion & $22 * / 98$ & 22.4 & 4 & 4 & 4 & 11 & {$[36,40,43,54,79,100]$} \\
Panthera pardus & Leopard & $2 * / 7$ & 28.6 & 1 & 1 & 1 & 0 & {$[38,54,101]$} \\
Varanus niloticus & Nile monitor & $1 / 2$ & NC & 1 & - & - & - & {$[4$} \\
Crocuta crocuta & Spotted hyaena & $17 / 26$ & 65.4 & 2 & - & 1 & 14 & {$[54,100]$} \\
Felis silvestris lybica & African Wildcat & $1 / 1$ & NC & - & - & - & 1 & {$[54]$} \\
Canis mesomelas** & Black-backed jackal & $1 / 2$ & NC & - & - & - & 1 & {$[100]$} \\
Civettictis civetta & African civet & $1 / 2$ & NC & - & - & - & 1 & {$[54,101]$} \\
Genetta genetta & Small spotted genet & $1 / 2$ & NC & 1 & - & - & 0 & {$[54]$} \\
Papio ursinus & Chacma baboon & $1 / 6$ & 16.7 & - & - & - & 1 & {$[54]$} \\
Praomys natalensis & Multimammate mouse & $1 / 44$ & 2.3 & - & - & - & 1 & {$[100]$} \\
Crocodylus niloticus & Nile crocodile & $16 / 43$ & 37.2 & 16 & - & - & - & {$[35,37,54]$} \\
Asio capensis & Marsh owl & $1 / 1$ & NC & - & - & - & 1 & {$[54]$} \\
Total & & $65 / 234$ & & 25 & 5 & 6 & 31 &
\end{tabular}

$\mathrm{Tz}=$ Trichinella zimbabwensis, $\mathrm{Tn}=$ Trichinella nelsoni, $\mathrm{T} 8=$ Trichinella genotype $\mathrm{T} 8, \mathrm{NID}=$ Not identified to species level;

* One animal represents a mixed infection of Trichinella nelsoni and Trichinella T8;

** Incorrectly reported as Side striped jackal (Canis adustus) by Marucci et al. [43] and Mukaratirwa et al. [53], NC = Not calculated due to sample size $<5$.

Table 3. Occurrence of Trichinella spp. in wildlife species from sub-Saharan Africa other than Kruger National Park, South Africa.

\begin{tabular}{|c|c|c|c|c|c|c|c|c|c|c|}
\hline $\begin{array}{l}\text { Country of } \\
\text { origin }\end{array}$ & Animal species & Common name & $\begin{array}{l}\text { No positive/ } \\
\text { tested }\end{array}$ & $\begin{array}{c}\text { Total } \\
\text { prevalence } \\
(\%)\end{array}$ & $\mathrm{Tz}$ & Tn & $\mathrm{T} 8$ & $\mathrm{~Tb}$ & NID & References \\
\hline Tanzania & Panthera leo & Lion & $3 / 24$ & 12.5 & - & 3 & - & - & - & [67] \\
\hline Namibia & & & $1 / 1$ & $\mathrm{NC}$ & - & - & 1 & - & - & [40], ITRC \\
\hline Tanzania & Panthera pardus & Leopard & $1 / 3$ & $\mathrm{NC}$ & - & 1 & - & - & - & [67] \\
\hline Kenya & & & $1 / 4$ & $\mathrm{NC}$ & - & 1 & - & - & - & {$[56,66]$} \\
\hline Zimbabwe & Varanus niloticus & Nile monitor & $6 / 29$ & 20.7 & 6 & - & - & - & - & {$[53,68]$} \\
\hline Tanzania & Crocuta crocuta & Spotted hyaena & $3 / 13$ & 23 & - & 3 & - & - & - & [67] \\
\hline Congo & & & $1 / 1$ & $\mathrm{NC}$ & - & - & - & - & 1 & [101] \\
\hline Kenya & & & $1 / 1$ & $\mathrm{NC}$ & - & 1 & - & - & - & [66], ITRC \\
\hline Namibia & & & $1 / ?$ & $\mathrm{NC}$ & - & - & - & - & 1 & [79] \\
\hline Senegal & Canis adustis & Side-striped jackal & $1 / 10$ & 10 & - & - & - & - & 1 & [18] \\
\hline Kenya & & & $?$ & $\mathrm{NC}$ & - & - & - & - & - & [66] \\
\hline Namibia & Canis mesomelas & Black-backed jackal & $1 / ?$ & $\mathrm{NC}$ & - & - & - & - & 1 & [79] \\
\hline Tanzania & & & $1 / 11$ & 9 & - & - & - & - & 1 & [86] \\
\hline Senegal & Ichneumia albicauda & $\begin{array}{l}\text { White-tailed } \\
\text { mongoose }\end{array}$ & $6 / 17$ & 35.3 & - & - & - & - & 6 & [18] \\
\hline Guinea & Civettictis civetta & African civet & $1 / 19$ & 5.3 & - & - & - & 1 & - & [78] \\
\hline Guinea & Nandinia binotata & African palm civet & $2 / 45$ & 4.4 & - & - & - & 1 & - & [78] \\
\hline Kenya & $\begin{array}{l}\text { Potamochoerus } \\
\quad \text { larvatus }\end{array}$ & Bush pig & $1 / 40$ & 2.5 & - & - & - & - & 1 & {$[56]$} \\
\hline Kenya & Phacochoerus africanus & Warthog & $18 / 450$ & 4 & - & - & - & - & 18 & [18] \\
\hline Tanzania & & & $1 / 1$ & $\mathrm{NC}$ & - & 1 & - & - & - & [38], ITRC \\
\hline Zimbabwe & Crocodylus niloticus & Nile crocodile & $256 / 648$ & 39.5 & 256 & - & - & - & - & [15] \\
\hline Mozambique & & & $8 / 40$ & 20 & 8 & - & - & - & - & {$[68]$} \\
\hline Tanzania & Acinonyx jubatus & Cheetah & $1 / 5$ & 20 & - & 1 & - & - & - & [67] \\
\hline Kenya & Leptailurus serval & Serval & $1 / 9$ & 11 & - & 1 & - & - & - & {$[56,66]$} \\
\hline Tanzania & Otocyon megalotis & Bat-eared fox & $1 / 6$ & 17 & - & 1 & - & - & - & [67] \\
\hline Kenya & Hyaena hyaena & Striped hyaena & $1 / 2$ & 50 & - & 1 & - & - & - & {$[56,66]$} \\
\hline Nigeria & Cricetomys gambianus & African giant rat & $16 / 100$ & 16 & - & - & - & - & 16 & [46] \\
\hline \multirow[t]{2}{*}{ Nigeria } & Sus domesticus & Domestic pigs & $42 / 883$ & 4.8 & - & - & - & - & 42 & {$[2]$} \\
\hline & Total & & $379 / 2362$ & 16 & 270 & 15 & 1 & 2 & 88 & \\
\hline
\end{tabular}

$\mathrm{Tz}=$ Trichinella zimbabwensis, $\mathrm{Tn}=$ Trichinella nelsoni, $\mathrm{T} 8=$ Trichinella genotype $\mathrm{T} 8, \mathrm{~Tb}=$ Trichinella britovi, NID $=$ Not identified to species level, $\mathrm{NC}=$ Not calculated/reported due to sample size $<5$. ITRC $=$ International Trichinella Reference Centre, $?=$ Actual numbers not reported in cited literature. 


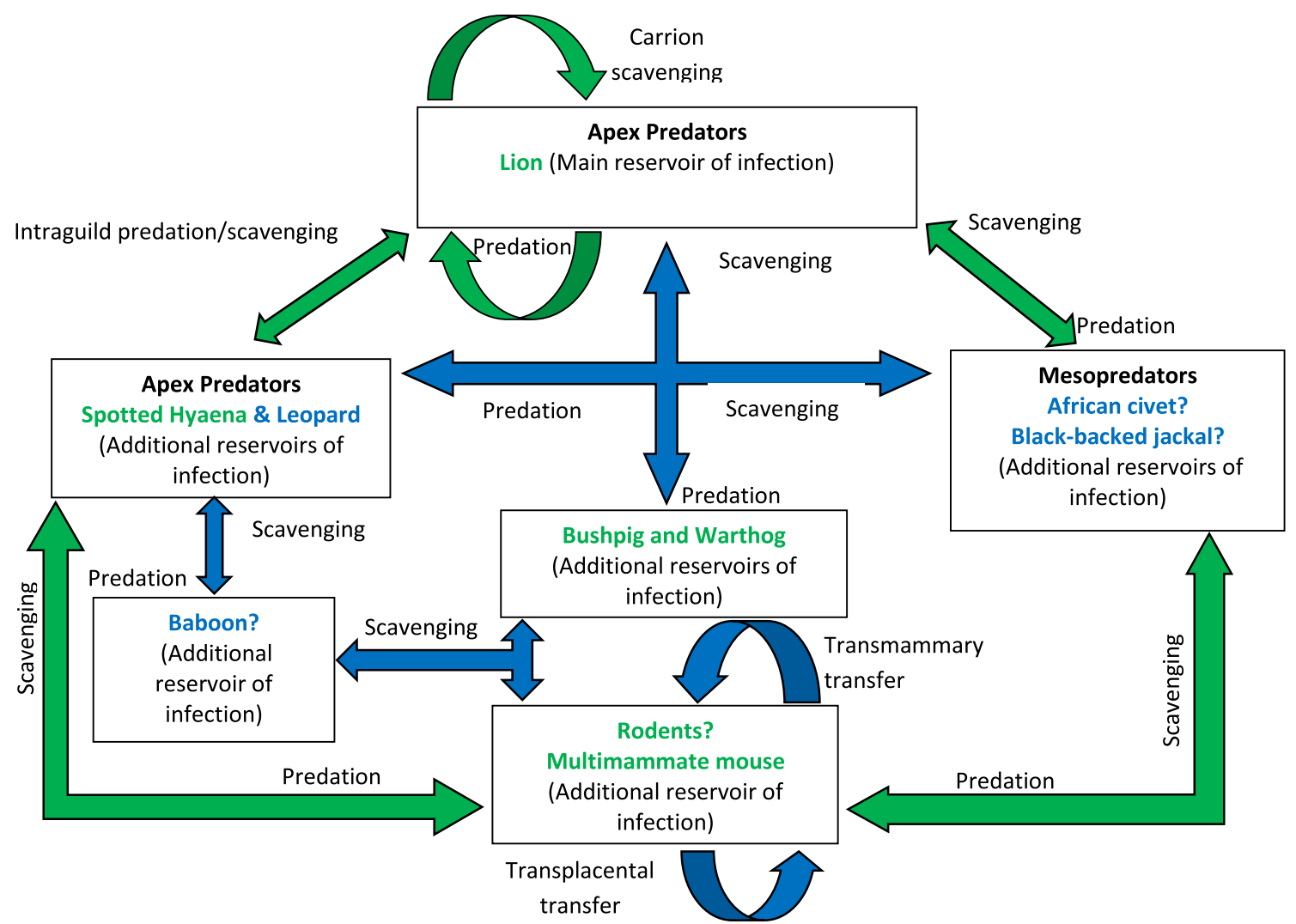

Figure 2. Updated hypothetical sylvatic cycle of Trichinella nelsoni and Trichinella T8 in the Greater Kruger National Park (GKNP) of South Africa. ? = Species involvement is yet to be confirmed; Arrows indicate direction of transmission; Arrows in green colour = Previously hypothesised mode of transmission (Mukaratirwa et al. [53]); Arrows in blue colour = Additional hypothesised mode of transmission (current hypothesis); Host species in green text $=$ Previously hypothesized host species (Mukaratirwa et al. [53]); Host species in blue text without $?=$ Additional host(s) species (current hypothesis).

beyond its north-western- and southern boundaries [35, 37, 54], and in a Nile monitor lizard (Varanus niloticus) from the city of Nelspruit located close to the south-western border of the KNP [54]. Furthermore, it has also been detected in farmed crocodiles in South Africa (Department of Agriculture, Forestry and Fisheries (DAFF), personal communication). This species is infective to mammals and reptiles [51-53, 74]. Results from passive surveillance in the GKNP further revealed that $T$. zimbabwensis has the highest prevalence in crocodiles and carnivores, of three species known to circulate in South Africa [54].

\section{Hypothetical transmission cycles of Trichinella spp. in GKNP}

Previous findings have prompted speculation concerning the epidemiology of T. nelsoni, Trichinella T8 and T. zimbabwensis, including hypothetical transmission cycles as proposed by Mukaratirwa et al. [53]. Since the publication of these hypotheses, new host species have been confirmed [54], prompting a revision of the proposed hypotheses. Unravelling the enigmatic epidemiology of these potentially zoonotic species from the genus Trichinella is important from a public health perspective as it aids in establishing not only the potential risk for human infection [63], but ultimately proper control and prevention measures [53, 64, 80].
New additions to the knowledge on the prevalence of Trichinella spp. isolated from wildlife hosts in the GKNP and other surrounding areas outside the park and elsewhere in Eastern and Southern Africa provides for an update of the previously hypothesised transmission cycles for the three taxa known to circulate in this area. Considering the potential epidemiological drivers based on host species richness and interspecies interaction in the GKNP and the region discussed earlier, hypothetical transmission cycles for the three Trichinella taxa are proposed in Figures 2 and 3.

Based on the sympatric existence of $T$. nelsoni and Trichinella T8, we hypothesize a transmission cycle applicable to both these species (Fig. 2). The hypothetical cycle previously presented by Mukaratirwa et al. [53] was updated to include recent findings presented by Mukaratirwa et al. [54]. A separate hypothetical cycle is presented for T. zimbabwensis (Fig. 3), and was similarly updated from Mukaratirwa et al. [53] to include recent findings [54]. Two apex predators (hyaena and leopard) and a mesopredator, the small spotted genet (Genetta genetta) have been confirmed as new host species and included in the hypothetical transmission cycle. Additionally, rodents and in particular the multimammate mouse (Praomys natalensis) [100] and three mesopredators, the African civet (Civettictis civetta) [101], black-backed jackal (Canis mesomelas) [100] and African wild cat (Felis silvestris lybica) [54], which were previously found to be infected by unidentified species of 


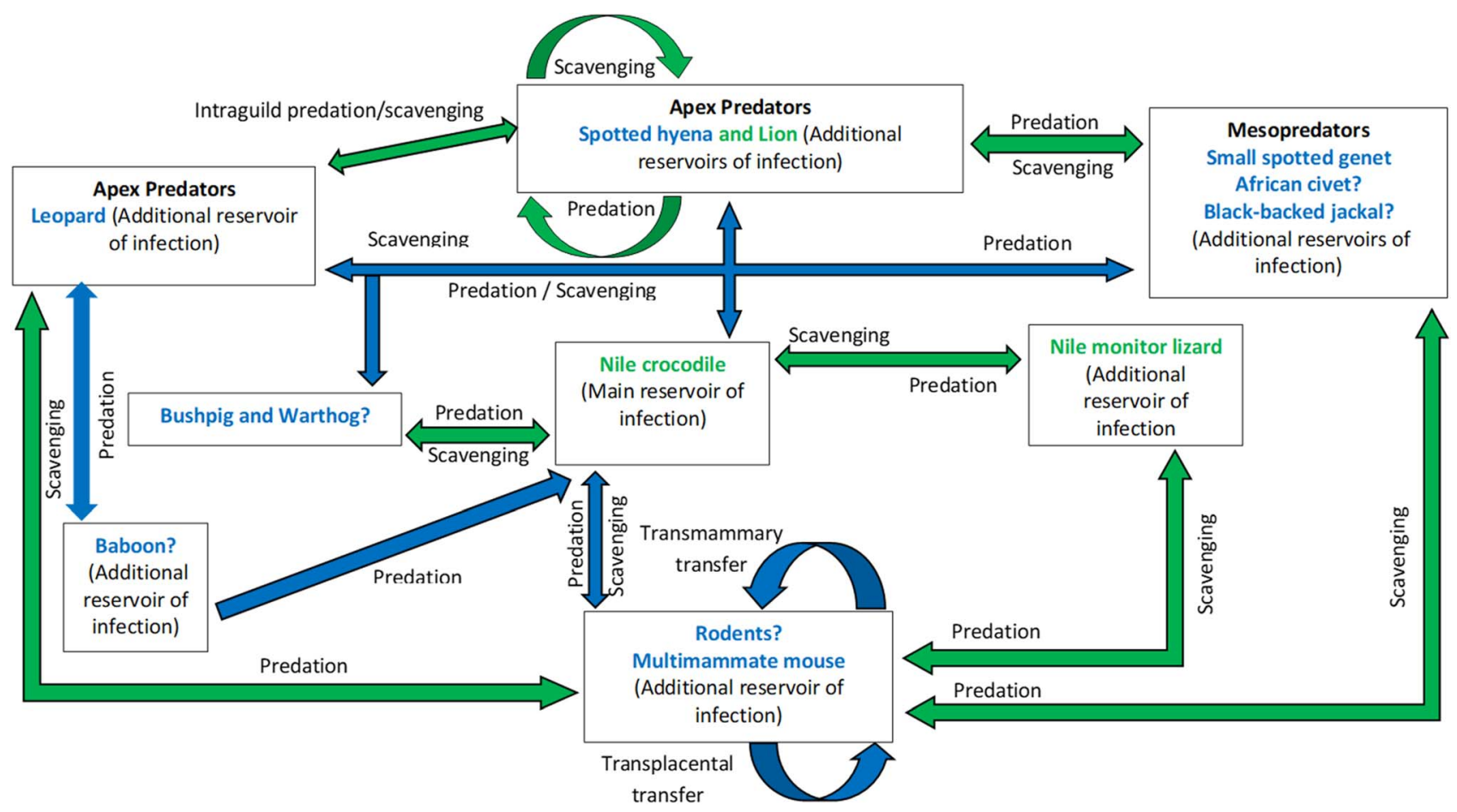

Figure 3. Updated hypothetical sylvatic cycle of Trichinella zimbabwensis in the Greater Kruger National Park (GKNP) of South Africa. ? = Species hypothesized to be involved but yet to be confirmed; Arrows indicate direction of transmission; Arrows in green colour = Previously hypothesised mode of transmission (Mukaratirwa et al. [53]); Arrows in blue colour = Updated hypothesised mode of transmission (current hypothesis); Host species in green text = Confirmed host species (Mukaratirwa et al. [53]); Host species in blue text without $?=$ Updated confirmed host(s) species (current hypothesis).

Trichinella, have been added as probable host species in both hypothetical cycles.

Interspecies predation between hyaenas and lions has previously been presented as a contributing factor in the maintenance of the two encapsulated Trichinella species, T. nelsoni and Trichinella T8 found in GKNP [53]. Results reported by Mukaratirwa et al. [54] now also suggest that T. zimbabwensis could be similarly maintained between these species. The addition of a leopard as a host for T. zimbabwensis, however, compels its inclusion into this equation. However, several factors that drive intraguild predation as discussed by Palomares and Caro [60] need to be taken into account. The interactive role of leopards may be predominantly asymmetrical with leopards being more prone to predation by the other two species compared to a more symmetrical interaction between lions and hyaenas. However, as predators, leopards play a much more significant role in Trichinella epidemiology when considering their interaction with smaller mesopredators, such as the small spotted genet. Mukaratirwa et al. [54] also alluded to the importance of mesopredators as sources of infection to larger species and the possible existence of a large parasite biomass in rodents and reptiles that could act as a primary infection source.

\section{Discussion}

Parasites of the genus Trichinella are known to primarily infect sylvatic carnivores with cannibalistic and/or scavenger behaviour $[9,53,75]$. Domestic cycles involving some species, most notably $T$. spiralis are recognised $[19,64]$ and intrusion from the sylvatic cycle into the domestic environment usually results from human failure to properly manage the wildlifedomestic animal interface [75]. Pozio [64] noted that successful intrusion from the sylvatic cycle and the subsequent maintenance of the flow of parasites between sylvatic, synanthropic and domestic environments relies on parasite and ecological characteristics, human behaviour and availability of synanthropes. This would ultimately result in unique life cycles for each taxon within a specific ecological niche. Trichinella nelsoni is known to occur in Eastern and Southern Africa [53, 78] and has been detected in Kenya, Tanzania and South Africa [38, 43, 54, 67, 79]. Carnivores appear to be the major reservoirs for $T$. nelsoni and the parasite has been found in high prevalence especially in lions (Panthera leo) (35.3\%) and spotted hyaenas (Crocuta crocuta) (29.4\%) [53]. It has additionally been detected in leopards (Panthera pardus) [38, 67], cheetahs (Acinonyx jubatus) and bat eared foxes (Otocyon megalotis) [67].

Despite high infectivity to carnivores, members of the Suidae family are only moderately susceptible to $T$. nelsoni $[28,29]$. These findings are supported by the fact that the actual prevalence of Trichinella spp. in wild Suidae appears to be very low $[53,75]$. Despite the reported low infectivity of wild Suidae to T. nelsoni $[28,29]$, previous reports of infections in these animals $[18,56,75,79,86]$ suggest that they might, albeit to a lesser extent, play a role in the epidemiology of Trichinella spp. in the GKNP. Importantly, the aforementioned was discovered 
prior to the advent of molecular characterisation techniques, and thus the parasite species involved remain unknown although the involvement of $T$. nelsoni cannot be ruled out. The exception might be the studies by Grétillat and Chevalier [18], which were conducted in Senegal where the reported infections may have involved T. britovi.

In the Majete Wildlife Reserve in Kenya, interspecies cannibalism among warthogs (Phacochoerus africanus) was observed and predation by warthogs on hyaena cubs suggested as a contributing factor to the small hyaena population [84]. Apart from the incidences reported by Sachs [86], Trichinella spp. infection has never been reported in wild pigs from South Africa albeit that the numbers screened thus far have been very low [54].

Trichinella $\mathrm{T} 8$ has previously been isolated in a lion from the Etosha National Park in Namibia [75, 79], but surprisingly has never been positively identified in any other African country except South Africa [53, 66]. However, Marucci et al. [43] did observe that both T. nelsoni and Trichinella T8 appear to circulate among hyaenas and lions in the KNP with similar prevalence and hypothesized sympatric status. This sympatry is confirmed to extend to other host species and include leopards [38].

Results from passive surveillance in the GKNP revealed that T. zimbabwensis has the highest prevalence in Nile crocodiles and carnivores compared to the three species known to circulate in South Africa [54]. Trichinella zimbabwensis has also been detected in farmed crocodiles in South Africa (DAFF, personal communication). This parasite species was proved experimentally to be infective to mammals and reptiles [51-53, 70] and notably, domestic pigs [44, 52]. No known cases of human disease have been associated with $T$. zimbabwensis. However, its infectivity to pigs and other animal species utilized as human food sources provide the incentive to regard this species as a high risk species of food safety concern [13].

Moleón et al. [48] suggested the risk of parasitic infection associated with conspecific and heterospecific carrion scavenging between carnivores to be a selective force preventing carnivores from eating each other. However, in the case of Trichinella infections, predation and scavenging among carnivores is the primary mode of transmission and carnivores are the primary hosts [8]. Carnivores like lions and hyaenas are considered apex predators [60] and have a dietary overlap of more than $68 \%$ [20, 61]. Additionally, within the GKNP, these two predators both prefer the same habitat [61], which may result in encounters where kleptoparasitism by both species frequently occurs [41]. These encounters can prove fatal to individuals of both species although mortality of hyaenas is usually higher [61]. There is a paucity of literature on the actual incidence of intraguild predation with consumption of the victim by these two predators. Palomares and Caro [60] have shown that carnivores sometimes consume or at least partially consume their victims. This would suggest intraguild scavenging between carnivores to be secondary to active predation where the transmission of Trichinella spp. is concerned. However, secondary carrion scavenging by both apex- and mesopredators such as jackals (Canis mesomelas) on carnivore carcasses cannot be totally excluded.

Leopards ( $P$. pardus) are known to prey on smaller mesopredators $[4,22,42]$ and a review by Palomares and Caro
[60] showed that these opportunistic predators not only killed but consumed a variety of carnivore species, including young hyaenas [4]. Similarly, lions and hyaenas frequently kill and sometimes consume smaller mesopredators [60].

A previous study showed that odours, specifically 2-phenylethylamine, from carnivore carcasses trigger an innate fear response that leads to avoidance of carnivore carrion by rodents [14]. However, multimammate mice ( $P$. natalensis) are known to occur in the GKNP and their diet can include carrion [49]. This is also supported by the fact that a single case of Trichinella infection was previously reported in this species from the KNP [100]. Vertical transmission of T. zimbabwensis via the transmammary and transplacental routes has been experimentally proven in rodents (Rattus norvegicus) [45], which suggests that endemic rodent populations in the GKNP may play an integral role in the maintenance and transmission of the three Trichinella taxa known to circulate in the region.

In addition to the plethora of potential mammalian hosts, the GKNP is home to a high population of Nile crocodiles (C. niloticus) and predation between crocodiles and mammalian carnivores is known to occur [99]. Previous studies have shown a high prevalence of $T$. zimbabwensis in Nile crocodiles in the KNP [35]. This could probably be attributed to high levels of intraspecies predation and scavenging among crocodiles. However, a recent report by Mukaratirwa et al. [54] showed T. zimbabwensis not only to be the most prevalent, but also to infect the widest host range of all the Trichinella species isolated thus far from the GKNP. This would certainly suggest the general knowledge and perceptions of interspecies predation and scavenging to be incomplete.

\section{Limitations of the review}

Several factors preclude a co-ordinated surveillance effort to enable screening of all the potential host species in the GKNP and other nature reserves in the rest of South Africa and elsewhere. Access to a variety of samples is reliant on the acquisition of convenient samples from State Veterinary Services, reserve staff and private veterinarians. A more structured and co-ordinated approach such as the effective implementation of existing regulations [Regulation (EU) 2015/ 1375] employed in North America, Europe and Asia is required to maintain and improve wildlife surveillance for Trichinella infections in GKNP.

All potential stakeholders should be sensitized to the importance of surveillance through continued collaborative efforts. Many of the potential host species are also protected by national and international legislation, which further hampers sample acquisition. Overcoming legislative barriers can only be attained through close collaboration with local authorities. Establishing effective communication between researchers and other stakeholders with the applicable authorities mandated to regulate the collection and transportation of samples is essential to future success. Lack of funding and other resources also precludes effective surveillance. Private and institutional funding opportunities should continually be sought and motivated through highlighting the potential impact of Trichinella on human health and the threat to commercial farming industries. 
Indeed, the lack of data on human infections and cases involving domestic animals has resulted in Trichinella surveillance not being considered a public health priority by the controlling veterinary authority. This perception needs to be changed and emphasis must be placed on the marginal cost of surveillance compared to the cost of remedial action in the event of a human outbreak, or the cost of control and eradication in the event of domestic spill-over.

\section{Research gaps and future research}

Maintenance of, and where possible, improvement of collaborative efforts with GKNP staff and other stakeholders is crucial. Wildlife surveillance should also be encouraged in other African countries and the rest of South Africa, and hence there is need to employ current knowledge and expertise to establish a Trichinella Reference Centre for Africa to assist in the surveillance of infections and capacity building of expertise.

A study on the role of predatory fish as potential hosts for T. zimbabwensis is currently underway in South Africa. A previous study suggests that fish do not play any significant role in the epidemiology of T. zimbabwensis [72]. However, the potential host species used in the study are not associated with either Nile crocodiles or Nile monitor lizards in nature and do not co-exist with any of the predators in any of their respective natural habitats. Previous studies have shown that host characteristics play an important role in determining not only muscle predilection but also the infectivity of different Trichinella species to different hosts [30, 31, 37, 83, 93]. Studies with fish experimentally infected with encapsulated $T$. britovi and $T$. spiralis and non-encapsulated T. pseudospiralis did show that the larvae, even though they did not develop into adults, migrated to the body cavity and internal organs ( $T$. spiralis) and also the muscles (T. britovi and T. pseudospiralis) of some fish species and retained their infectivity for a limited period of time [50, 97]. However, interspecies differences between parasites of the genus Trichinella have also been shown to influence both muscle predilection and infectivity in the same host $[25,32,33]$. In order to fully understand parasite epidemiology, the correct selection of a probable host species and parasite species based on their natural occurrence is of utmost importance.

Future surveillance efforts will also include more focused efforts on migratory carnivorous birds and targeted surveillance of rodents to elucidate their potential role as maintenance reservoirs for the different Trichinella taxa in GKNP.

\section{Conclusion}

The vast size and limited human interference combined with the species richness within the protected area of the GKNP provide an excellent setting for the establishment and maintenance of the Trichinella spp. known to circulate in the area. As a testament to this, T. zimbabwensis, T. nelsoni and Trichinella T8 have all established very unique and diverse transmission and maintenance cycles consisting of a multitude of equally diverse host species. Results from surveys spanning more than 50 years suggest that our knowledge of the actual incidence and epidemiology of Trichinella in this area is curtailed at best. As such, the information presented here cannot, by any means, be considered complete but should rather be viewed as ongoing which undoubtedly will require future update as new evidence is presented. Despite much of the information presented being based on anecdotal evidence, this study confirms not only a need for more intense epidemiological surveillance in the rest of South Africa and beyond [53], but also the need for continued efforts to unravel the remaining gaps in the epidemiology of Trichinella spp. in these unique and diverse protected landscapes in eastern and southern Africa.

Acknowledgements. Our sincere appreciation to the Mpumalanga Department of Agriculture, Rural Development, Land and Environmental Affairs for logistical and financial support provided through the Chief Directorate of Veterinary Services; Dr. J.P. Raath and staff of Wildlifevets.com and Wildlife Pharmaceuticals for financial, logistical and technical support provided. Thanks are also due to the staff and students of the School of Life Sciences, University of KwaZulu-Natal for their continued support and assistance in testing research samples, SANPARKS, KNP, and adjoining Nature reserves staff for the continued collection of samples.

\section{Financial support}

This study was supported in part by the Mpumalanga Department of Agriculture, Rural Development, Land and Environmental Affairs as part of a continuous surveillance project and by Wildlife Pharmaceuticals Pty (Ltd).

\section{Conflicts of interest}

The authors declare that they have no conflict of interest.

\section{References}

1. Abu Baker M, Brown JS. 2010. Islands of fear: effects of wooded patches on habitat suitability of the striped mouse in a South African grassland. Functional Ecology, 24, 1313-1322.

2. Akinboade OA, Awotoye A, Dipeolu OO. 1984. Prevalence of trichinosis in pigs in Oyo State of Nigeria. Annales de la Société Belge de Médecine Tropicale, 64, 315-318.

3. Atkinson RPD, Macdonald DW, Kamizola R. 2002. Dietary opportunism in side-striped jackal Canis adustis Sundevall. Journal of Zoology, 257, 129-139.

4. Bailey TN. 1993. The African leopard: ecology and behaviour of a solitary felid. Columbia University Press: New York, p. 429.

5. du Bothma J du P. 1971. Food habits of some carnivora (Mammalia) from southern Africa. Annals of the Transvaal Museum, 27, 15-26.

6. Britov VA, Boev SN. 1972. Taxonomic rank of various strains of Trichinella and their circulation in nature. Vestnik Akademii Nauk KSSR, 28, 27-32.

7. Busse C. 1980. Leopard and lion predation upon chacma baboons living in the Moremi Wildlife Reserve. Botswana Notes \& Records, 12, 15-21.

8. Campbell WC. 1988. Trichinosis revisited, another look at modes of transmission. Parasitology Today, 4, 83-86. 
9. Cumming DHM. 1975. A field study of the ecology and behaviour of warthog. The Trustees of the National Museums and Monuments of Rhodesia Salisbury. Rhodesia, Museum Memoir No 7, p. 179.

10. Davidson Z, Valeix M, Van Kesteren F, Loveridge AJ, Hunt JE, Murindagomo F, Macdonald DW. 2013. Seasonal diet and prey preference of the African lion in a waterhole-driven semi-arid savanna. PLoS One, 8, e55182.

11. Do Linh San E, Stuart C, Stuart M. 2016. A conservation assessment of Ichneumia albicauda, in The Red List of Mammals of South Africa, Swaziland and Lesotho. Child MF, Roxburgh L, Do Linh San E, Raimondo D, Davies-Mostert HT, Editors. South Africa: South African National Biodiversity Institute and Endangered Wildlife Trust. p. 4.

12. Engering A, Hogerwerf L, Slingenbergh J. 2013. Pathogenhost-environment interplay and disease emergence. Emerging Microbes and Infections, 2, e5.

13. FAO. 2013. Summary risk profile on Trichinella in meat. http://www.fao.org/fileadmin/user_upload/agns/pdf/Foodborne_ parasites/RiskProfTrichinellaOct2013.pdf.

14. Ferrero DM, Lemon JK, Fluegge D, Pashkovski SL, Korzan WJ, Datta SR, Spehr M, Fendt M, Liberies SD. 2011. Detection and avoidance of a carnivore odor by prey. Proceedings of the National Academy of Sciences, 108, 11235-11240.

15. Foggin CM, Vassilev GD, Widdowson MA. 1997. Infection with Trichinella in farmed crocodiles ( $C$. niloticus) in Zimbabwe, in Abstract Book on the 16th International Conference of the World Association for the Advancement of Veterinary Parasitology, Sun City, South Africa, 10-15 August (Abstract no. 110).

16. Furstenburg D. 2008. Crocodile (Crocodylus niloticus). Game \& Hunt, 14, 6-12.

17. Garkavi BL. 1972. Species of Trichinella isolated from wild animals. Veterinariya, 10, 90-91.

18. Grétillat S, Chevalier JL. 1970. Note préliminaire sur l'épidémiologie de la trichinose des animaux sauvages en Afrique de l'Ouest. Bulletin of the World Health Organization, 43, 749-757.

19. Gottstein B, Pozio E, Nöckler K. 2009. Epidemiology, diagnosis, treatment, and control of trichinellosis. Clinical Microbiology Reviews, 22, 127-145.

20. Hayward MW. 2006. Prey preferences of the spotted hyaena (Crocuta crocuta) and degree of dietary overlap with the lion (Panthera leo). Journal of Zoology, 270, 606-614.

21. Hayward M, Kerley IH. 2005. Prey preferences of the lion (Panthera leo). Journal of Zoology, 267, 309-322.

22. Hayward MW, Henschel P, O'Brien J, Hofmeyr M, Balme G, Kerley GIH. 2006. Prey preferences of the leopard (Panthera pardus). Journal of Zoology, 270, 298-313.

23. Hayward MW, Porter L, Lanszki J, Kamler JF, Beck JM, Kerley IH, Macdonald DW, Montgomery RA, Parker DM, Scott DM, O'Brien J, Yarnell RW. 2017. Factors affecting the prey preferences of jackals (Canidae). Mammalian Biology, 85, 70-82.

24. Herbst M, Mills MGL. 2010. The feeding habits of the African wild cat (Felis silvestris), a facultative trophic specialist, in the southern Kalahari (Kgalagadi Transfrontier Park, South Africa/ Botswana). Journal of Zoology, 280, 403-413.

25. Hurníková Z, Dubinsky S, Mukaratirwa S, Foggin CM, Kapel CMO. 2004. Infectivity and temperature tolerance on nonencapsulating Trichinella zimbabwensis in experimentally infected Red foxes (Vulpes vulpes). Helminthologia, 41, 189-192.

26. Isaäcson M. 1975. The ecology of Praomys (Mastomys) natalensis in southern Africa. Bulletin of the World Health Organization, 52, 629-636.
27. Jooste E, Pitman RT, van Hoven W, Swanepoel LH. 2012. Unusually high predation on chacma baboons (Papio ursinus) by female leopards (Panthera pardus) in the Waterberg Mountains, South Africa. Folia Primatologica, 83, 353-360.

28. Kapel CMO. 2000. Host diversity and biological characteristics of the Trichinella genotypes and their effect on transmission. Veterinary Parasitology, 93, 263-278.

29. Kapel CMO, Gamble HR. 2000. Infectivity, persistence, and antibody response to domestic and sylvatic Trichinella spp. in experimentally infected pigs. International Journal for Parasitology, 30, 215-221.

30. Kapel C, Henrikson SA, Dietz HH, Henrikson P, Nansen P. 1994. A study on the predilection sites of Trichinella spiralis larvae in experimentally infected foxes (Alopex lagopus, Vulpes vulpes). Acta Veterinaria Scandinavica, 35, 125-132.

31. Kapel C, Henrikson SA, Berg TB, Nansen P. 1995. Trichinella infections in Arctic foxes from Greenland: Studies and reflections on predilection sites of muscle larvae. Journal of Helminthology, 69, 325-330.

32. Kapel C, Webster P, Gamble H. 2005. Muscle distribution of sylvatic and domestic Trichinella larvae in production animals and wildlife. Veterinary Parasitology, 132, 101-105.

33. Kocieska W, van Knapen F, Ruitenberg EJ. 1980. Trichinella pseudospiralis and T. spiralis infections in monkeys, I: Parasitological aspects, in Proceedings of the Fifth International Conference on Trichinellosis, September 1-5, 1980, Noordwijk aan Zee, The Netherlands. Kim CW, Ruitenberg EJ, Teppema JS, Editors. p. 199-202.

34. Krivokapich SJ, Pozio E, Gatti GM, Gonzales Prous CL, Ribicich M, Marucci G, La Rosa G, Cofalonieri V. 2012. Trichinella patagoniensis $\mathrm{n}$. sp. (Nematoda), a new encapsulated species infecting carnivorous mammals in South America. International Journal for Parasitology, 42, 903-910.

35. La Grange LJ, Marucci G, Pozio E. 2009. Trichinella zimbabwensis in wild Nile crocodiles (Crocodylus niloticus) of South Africa. Veterinary Parasitology, 161, 88-91.

36. La Grange LJ, Marucci G, Pozio E. 2010. Trichinella zimbabwensis in a naturally infected mammal. Journal of Helminthology, 35-38.

37. La Grange LJ, Govender D, Mukaratirwa S. 2013. The occurrence of Trichinella zimbabwensis in naturally infected wild crocodiles (Crocodylus niloticus) from the Kruger National Park, South Africa. Journal of Helminthology, 87, 91-96.

38. La Grange LJ, Reininghaus B, Mukaratirwa S. 2014. First report of a mixed infection of Trichinella nelsoni and Trichinella T8 in a leopard (Panthera pardus) from the Greater Kruger National Park, South Africa. Onderstepoort Journal of Veterinary Research, 81, 8-10.

39. Lariviere S, Calzada J. 2001. Genetta genetta. Mammalian Species, 680, 1-6.

40. La Rosa G, Pozio E. 2000. Molecular investigation of African isolates of Trichinella reveals genetic polymorphism in Trichinella nelsoni. International Journal for Parasitology, 30, 663-667.

41. Lehmann KDS, Montgomery TM, McLachlan SM, Parker JM, Spagnuolo OS, VandeWetering KJ, Bills PS, Holekamp KE. 2017. Lions, Hyenas and mobs (oh my!). Current Zoology, 63, 313-322.

42. Le Roux PG, Skinner JD. 1989. A note on the ecology of the leopard (Panthera pardus Linnaeus) in the Londolozi Game Reserve, South Africa. African Journal of Ecology, 27, 167-171.

43. Marucci G, La Grange LJ, La Rosa G, Pozio E. 2009. Trichinella nelsoni and Trichinella T8 mixed infection in a lion (Panthera leo) of the Kruger National Park (South Africa). Veterinary Parasitology, 159, 225-228. 
44. Matenga E, Mukaratirwa S, Bhebhe E, Willingham AL. 2006a. Comparison of the infectivity of Trichinella zimbabwensis in indigenous Zimbabwean pigs (Mukota) and exotic Large White pigs. International Journal of Applied Research in Veterinary Medicine, 4, 301-306.

45. Matenga E, Mukaratirwa S, Bhebhe E, Willingham AL. 2006b. Evidence of congenital and transmammary transmission of Trichinella zimbabwensis in rats (Rattus norvegicus) and its epidemiological implications. International Journal of applied Research in Veterinary Medicine, 4, 307-312.

46. Mbaya W, Ahmed MI, Ibrahim UI, Larmude KJ. 2010. Trichinosis in African giant rats (Cricetomys gambianus) in the arid region of north eastern Nigeria. Journal of Medicine and Medical Sciences, 1, 460-464.

47. Mills MGL, Broomhall LS, du Toit JT. 2004. Cheetah Acinonyx jubatus feeding ecology in the Kruger National Park and a comparison across African savannah habitats: Is the cheetah only a successful hunter on open grassland plains? Wildlife Biology, 10, 177-186

48. Moleón M, Martinez-Carrasco C, Muellerklein OC, Getz WM, Muloz-Lozano C, Sánchez-Zapata JA. 2017. Carnivore carcasses are avoided by carnivores. Journal of Animal Ecology, 86, 1179-1191.

49. Monadjem A, Taylor PJ, Denys C, Cotterill FPD. 2015. Rodents of sub-Saharan Africa: A biogeographic and taxonomic synthesis. De Gruyter: Berlin, Boston. p. 1092. ISBN 978-3-11-030191-5.

50. Moretti A, Piergili-Fioretti D, Pasquali P, Mechelli L, Rossodivita ME, Polidori GA. 1997. Experimental infection of fish with Trichinella britovi: Biological evaluations, in Trichinellosis. Ortega-Pierres G, Gamble HR, van Knapen F, Wakelin D, Editors. Centro de Investigacion y Estudios Avanzados IPN: Mexico City. p. 135-142.

51. Mukaratirwa S, Dzoma B. 2008. Experimental infections of baboons (Papio spp.) and vervet monkeys (Cercopithecus aethiops) with Trichinella zimbabwensis and successful treatment with ivermectin. Onderstepoort Journal of Veterinary Research, 188, 181-188.

52. Mukaratirwa S, Foggin CM. 1999. Infectivity of Trichinella sp. isolated from Crocodylus niloticus to the indigenous Zimbabwean pig (Mukota). International Journal for Parasitology, 29, $1129-1131$

53. Mukaratirwa S, La Grange L, Pfukenyi DM. 2013. Trichinella infections in animals and humans in sub-Saharan Africa: A review. Acta Tropica, 125, 82-89.

54. Mukaratirwa S, La Grange LJ, Malatji MP, Reininghaus B, Lamb J. 2019. Prevalence and molecular identification of Trichinella species isolated from wildlife originating from Limpopo and Mpumalanga Provinces of South Africa. Journal of Helminthology, 93, 50-56.

55. Nagano I, Wu Z, Matsuo A, Pozio E, Takahashi Y. 1999. Identification of Trichinella genotypes by polymerase chain reaction - restriction fragment length polymorphism of mitochondrial cytochrome c oxidase subunit I gene. International Journal for Parasitology, 29, 1113-1120.

56. Nelson GS, Guggisberg CWA, Mukundi J. 1963. Animal hosts of Trichinella spiralis in East Africa. Annals of Tropical Medicine and Parasitology, 57, 332-346.

57. Nishank SS, Swain S. 2019. Cannibalism in animals. Science Horizon, 4, 33-39.

58. OIE - World Organisation for Animal Health. 2019. https:// www.oie.int/index.php?id=169\&L=0\&htmfile=chapitre_diagnostic_tests.htm.

59. Owen R. 1835. Description of a microscopic entozoon infesting the muscles of the human body. Transactions of the Zoological Society of London, 1, 315-324.
60. Palomares F, Caro TM. 1999. Interspecific killing among mammalian carnivores. American Naturalist, 153, 492-508.

61. Périquet S, Fritz H, Revilla E. 2015. The lion king and the hyaena queen: large carnivore interactions and coexistence. Biological Reviews, 90, 1197-1214.

62. de Pienaar U de V. 1964. The small mammals of the Kruger National Park - A systematic list and zoogeography. Koedoe, 7, $1-25$.

63. Polis GA, Myers CA, Holt RD. 1989. The ecology and evolution of intraguild predation: Potential competitors that eat each other. Annual Review of Ecology, Evolution and Systematics, 20, 297-330.

64. Pozio E. 2000. Factors affecting the flow among domestic, synanthropic and sylvatic cycles of Trichinella. Veterinary Parasitology, 93, 241-262.

65. Pozio E. 2005. The broad spectrum of Trichinella hosts: from coldto warm-blooded animals. Veterinary Parasitology, 132, 3-11.

66. Pozio E. 2007. World distribution of Trichinella spp. infections in animals and humans. Veterinary Parasitology, 149, 3-21.

67. Pozio E, De Meneghi D, Roelke-Parker ME, La Rosa G. 1997. Trichinella nelsoni in carnivores from the Serengeti ecosystem, Tanzania. Journal of Parasitology, 83, 1195-1198.

68. Pozio E, Foggin CM, Gelanew T, Marucci G, Hailu A, Rossi P, Gómez-Morales M. 2007. Trichinella zimbabwensis in wild reptiles of Zimbabwe and Mozambique and farmed reptiles of Ethiopia. Veterinary Parasitology, 143, 305-310.

69. Pozio E, Foggin CM, Marucci G, La Rosa G, Sacchi L, Corona S, Rossi P, Mukaratirwa S. 2002. Trichinella zimbabwensis n. sp. (Nematoda), a new non-encapsulated species from crocodiles (Crocodylus niloticus) in Zimbabwe also infecting mammals. International Journal for Parasitology, 32, 1787-1799.

70. Pozio E, Hoberg E, La Rosa G, Zarlenga DS. 2009. Molecular taxonomy, phylogeny and biogeography of nematodes belonging to the Trichinella genus. Infection, Genetics and Evolution, 9, 606-616.

71. Pozio E, La Rosa G. 2000. Trichinella murrelli n. sp.: Etiological agent of sylvatic trichinellosis in temperate areas of North America. Journal of Parasitology, 86, 134-139.

72. Pozio E, La Rosa G. 2005. Evaluation of the infectivity of Trichinella papuae and Trichinella zimbabwensis for equatorial freshwater fishes. Veterinary Parasitology, 132, 113-114.

73. Pozio E, La Rosa G, Murrell KD, Lichtenfels JR. 1992. Taxonomic revision of the genus Trichinella. Journal of Parasitology, 78, 654-659.

74. Pozio E, Marucci G, Casulli A, Sacchi L, Mukaratirwa S, Foggin CM, La Rosa G. 2004. Trichinella papuae and Trichinella zimbabwensis induce infection in experimentally infected varans, caimans, puthons and turtles. Parasitology, 128, 333-342.

75. Pozio E, Murrell KD. 2006. Systematics and epidemiology of Trichinella. Advances in Parasitology, 63, 371-445.

76. Pozio E, La Rosa G, Rossi P, Murrell KD. 1992. Biological characterizations of Trichinella isolates from various host species and geographic regions. Journal of Parasitology, 78, 647-653.

77. Pozio E, Owen IL, La Rosa G, Sacchi L, Rossi P, Corona S. 1999. Trichinella papuae n. sp. (Nematoda), a new nonencapsulated species from domestic and sylvatic swine of Papua New Guinea. International Journal for Parasitology, 29, 1825-1839.

78. Pozio E, Pagani P, Marucci G, Zarlenga DS, Hoberg EP, De Menighi D, La Rosa G, Rossi L. 2005. Trichinella britovi etiological agent of sylvatic trichinellosis in the Republic of Guinea (West Africa) and a re-evaluation of geographical distribution for encapsulated species in Africa. International Journal for Parasitology, 35, 955-960. 
79. Pozio E, Verster A, Braack L, De Meneghi D, La Rosa G. 1994. Trichinellosis south of the Sahara, in Trichinellosis. Campbell CW, Pozio E, Bruschi F, Editors. Istituto Superiore di Sanità Press: Rome, Italy. p. 527-532.

80. Pozio E, Zarlenga DS. 2005. Recent advances on the taxonomy, systematic and epidemiology of Trichinella. International Journal for Parasitology, 35, 1191-1204.

81. Pozio E, Zarlenga DS. 2013. New pieces of the Trichinella puzzle. International Journal for Parasitology, 43, 983-997.

82. Ramesh T, Downs CT. 2015. Diet of serval (Leptailurus serval) on farmlands in the Drakensberg Midlands, South Africa. Mammalia, 79, 399-407.

83. Reina D, Munoz-Ojeda M, Serrano F. 1996. Experimental trichinellosis in goats. Veterinary Parasitology, 62, 125-132.

84. Retief F. 2016. The ecology of spotted hyena, Crocuta crocuta, in Majete Wildlife Reserve, Malawi. Thesis (MSc), Stellenbosch University, p. 137.

85. Rosenthal J. 2009. Climate change and the geographic distribution of infectious diseases. EcoHealth, 6, 489-495.

86. Sachs R. 1970. Zur Epidemiologie der Trichinellose in Afrika. Zeitschrift fur Tropenmedizin und Parasitologie, 20, 117-126.

87. SANPARKS. 2008. Kruger National Park Management Plan. SANPARKS: Pretoria, South Africa. p. 151.

88. Scholtz M, Kruger M, Saayman M. 2013. Understanding the reasons why tourists visit the Kruger National Park during a recession. Acta Commercii 13, 9 pages.

89. Sharma R. 2019. Trichinella species and Toxoplasma gondii in wolverine (Gulo gulo) from north western, Thesis (PhD). University of Saskatchewan, Saskatoon, Canada.

90. Sharma R, Konecsni K, Scandrett B, Thompson P, Hoberg EP, Bouchard E, Buhler K, Harms NJ, Kukka PM, Jung TS, Elkin B, Mulders R, Larter NC, Branigan M, Pongracz J, Wagner B, Fenton H, Rosenthal BM, Jenkins E. 2019. Distribution and genetic diversity of Trichinella in Canadian wildlife: A previously undescribed species (T13) and an unexpected discovery of $T$. spiralis. Scientia Parasitologica, $20,145-148$
91. Skinner JD, Breytenbach GJ, Maberly CTA. 1976. Observations on the ecology and biology of the bush pig (Potamochoerus porcus) Linn in the northern Transvaal. South African Journal of Wildlife Research, 6, 123-128.

92. Somaweera R, Brien M, Shine R. 2013. The role of predation in shaping crocodilian natural history. Herpetological Monographs, 27, 23-51.

93. Soule C, Dupouy-Camet J, Georges P, Ancelle T, Gillet JP, Vaissaire J, Delvigne A, Plateau E. 1989. Experimental trichinellosis in horses: Biological and parasitological evaluation. Veterinary Parasitology, 31, 19-36.

94. Stander PE. 1997. The ecology of lions and conflict with people in north-eastern Namibia, in Proceedings of a Symposium on Lions and Leopards as Game Ranch Animals, van Heerden J, Editor. Onderstepoort, p. 10-17.

95. Szczepaniuk K. 2011. "Varanus niloticus" (On-line), Animal Diversity Web. Accessed October 18, 2019 at https://animal diversity.org/accounts/Varanus_niloticus/b.

96. Thomson P. 2002. Otocyon megalotis (On-line), Animal Diversity Web. Accessed December 30, 2019 at https://animal diversity.org/accounts/Otocyon_megalotis/.

97. Tomašovičová O. 1981. The role of fresh water fish in transfer and maintenance of Trichinellae under natural conditions. Biolǒgia, 36, 115-125.

98. Wagner AP. 2006. Behavioral ecology of the striped hyena (Hyaena hyaena). PhD thesis, Montana State University, Bozeman, Montana. p. 182.

99. World Heritage Encyclopedia. 2017. Nile crocodile World Public Library, Article id WHEBN 001284973, Retrieved 4 December 2017.

100. Young E, Kruger SP. 1967. Trichinella spiralis (Owen, 1935) Railliet 1895. Infestation of wild carnivores and rodents in South Africa. Journal of the South African Veterinary Association, 38, 441-443.

101. Young E, Whyte IJ. 1975. Trichinosis (Trichinella spiralis infestations) in wild animals of the Kruger National Park. Journal of the South African Veterinary Association, 46, 233-234.

Cite this article as: La Grange LJ \& Mukaratirwa S. 2020. Epidemiology and hypothetical transmission cycles of Trichinella infections in the Greater Kruger National Park of South Africa: an example of host-parasite interactions in an environment with minimal human interactions. Parasite 27, 13.

\section{PARASTE}

An international open-access, peer-reviewed, online journal publishing high quality papers on all aspects of human and animal parasitology

Reviews, articles and short notes may be submitted. Fields include, but are not limited to: general, medical and veterinary parasitology; morphology, including ultrastructure; parasite systematics, including entomology, acarology, helminthology and protistology, and molecular analyses; molecular biology and biochemistry; immunology of parasitic diseases; host-parasite relationships; ecology and life history of parasites; epidemiology; therapeutics; new diagnostic tools.

All papers in Parasite are published in English. Manuscripts should have a broad interest and must not have been published or submitted elsewhere. No limit is imposed on the length of manuscripts.

Parasite (open-access) continues Parasite (print and online editions, 1994-2012) and Annales de Parasitologie Humaine et Comparée (1923-1993) and is the official journal of the Société Française de Parasitologie. 